\title{
DIREÇÃO DE ARTE E VIDEOGRAFISMO APLICADOS \\ À PRODUÇÃO DE CONTEÚDOS EM ANIMAÇÃO PARA DISPOSITIVOS MÓVEIS PORTÁTEIS: UM ESTUDO DE CASO
}

\author{
Adriano Chagas \\ Universidade Estácio de Sá \\ adriano.chagas@gmail.com \\ Rodrigo Soprana \\ Universidade Federal Fluminense \\ rodrigosoprana@gmail.com
}

\begin{abstract}
Resumo: Esta pesquisa analisa os filmes finalistas da edição de 2012 do festival de animação Celucine sob a ótica da direção de arte e do videografismo. A observação se propõe a delimitar as preocupações e parâmetros que envolvem a produção de conteúdo do gênero animação, voltado exclusivamente para dispositivos móveis portáteis. As novas formas de consumo contemporâneo de produtos audiovisuais, que têm como plataforma telas dos mais variados tamanhos também são abordadas. 0 estudo ainda define a metodologia e os objetivos da análise dos filmes concorrentes para tentar estabelecer uma diretriz a respeito desta essencial área de conhecimento na cadeia produtiva audiovisual contemporânea.
\end{abstract}

Palavras-chave: audiovisual, animação, direção de arte, videografismo, novas mídias.

Abstract: This research analyses the finalist films from the 2012 edition of the festival Celucine animation, from the viewpoint of art direction and videographism. The notice proposes to define the parameters and concerns involving the production of such content animation, dedicated exclusively to mobile handheld devices. The new forms of contemporary consumption of audiovisual products, whose platform screens of various sizes are also addressed. The study also defines the methodology and objectives of the analysis of the competing films to try to establish a guideline regarding this essential area of knowledge in contemporary audiovisual production chain.

Key words: audiovisual, animation, art direction, videographism, new media. 


\section{INTRODUÇÃO}

No cenário da convergência tecnológica, observa-se a diversificação crescente das formas de produção e veiculação de conteúdos audiovisuais. As bases da evolução deste processo estão no aumento da velocidade e da universalização do acesso à internet. Ao mesmo tempo, dispositivos móveis mais modernos e com maior capacidade de processamento chegam ao mercado. São novas plataformas para o escoamento de uma intensa produção de conteúdo de animação, nas suas muitas técnicas e temáticas.

A diversificação das formas de acesso frente à gama de dispositivos móveis é um ponto de interrogação importante no momento da concepção e produção destes conteúdos. Entre as dimensões das telas de aparelhos de telefonia celular e tablets, há espaço para o questionamento dos conceitos de direção de arte e de videografismo, com foco no consumo imagético de massa. Consequentemente, também, para a pesquisa, investigação e documentação das técnicas e referências utilizadas pelos produtores de conteúdo.

A amostra analisada é composta pelos filmes finalistas da categoria animação da edição 2012 do festival Celucine, um dos principais eventos do gênero no Brasil. A análise do conteúdo das obras realizadas e o cruzamento das referências bibliográficas neste campo de conhecimento poderão tornar viável a definição de um quadro mais fidedigno da vanguarda na animação no país.

Uma linha de análise dos conteúdos dos produtos audiovisuais pode ser definida pelo termo Gestalt, referência para fatores como exposição, meio, percepção, significado e outros elementos emocionais e fisiológicos, na obra de AZEVEDO. A conceituação de animação e do setor de direção de arte ocorre com os estudos de NESTERIUK, para o desenvolvimento do gênero, e BUTRUCE e JUSSAN, acerca do impacto visual de uma produção. As características das novas plataformas de distribuição de conteúdo são indicadas por SANTAELLA, enquanto autores como MACHADO e VÉLEZ servem de referência para a hipermídia, uma nova forma de pensar a criação de um conteúdo de animação, por meio da associação de textos, formas, sons e imagens. O conceito de transmídia, exploração dos mais recentes espaços midiáticos pelos novos conteúdos de animação, se apresenta relacionado aos estudos de BORGES, PUCCI JR. e SOBRINHO. Por fim, ARNHEIN apresenta parâmetros para um enquadramento da mensagem dentro do mosaico de experiências individuais.

A pesquisa também relaciona as características técnicas e estéticas dos cinco filmes da amostra, apresentando sua análise individual a partir da exposição de um determinado quadro. Ao mesmo tempo, constrói uma perspectiva dos elementos e fatores que poderão reger a produção de conteúdo audiovisual de animação voltado especificamente para os dispositivos móveis portáteis.

O presente estudo pode servir como referência de consulta e base para novas pesquisas nesta área de conhecimento e justifica o lançamento de um olhar acadêmico para o segmento de animação, ao mesmo tempo em que contribui para o reconhecimento do Brasil como território de excelência na produção artística e criativa para os novos meios. 


\section{CONCEITOS ASSOCIADOS À REALIZAÇÃO}

Pesquisadores e produtores de conteúdo audiovisual têm evidenciado esforços, ao longo dos anos, para estabelecer uma metodologia definitiva, ao estilo estruturalista, no processo de análise de produtos criativos. Algumas diretrizes são apresentadas pelos que aplicam a Gestalt em suas análises. Por mais que se busque esquematizar e enquadrar produtos em categorias e analisar seus potenciais, há um longo caminho a percorrer, no conhecimento da intrincada cadeia de ocorrências que envolvem exposição, meio, percepção, significação e os demais fatores emocionais e fisiológicos que se seguem ao processo de consumo de produtos audiovisuais.

\subsection{0 gênero animação}

Não é possível abordar a história do audiovisual sem citar Charles-Émille Reynaud, responsável pela primeira exibição pública de uma animação, na Paris de 1892. O relato simples de dia à beira de uma praia, registrado na obra de NESTERIUK (2011) inaugurou a arte da organização de fotogramas previamente planejados, a partir de uma técnica de desenho, para criar a sensação de movimento e veicular uma história. Atualmente, o uso do computador é corrente e sua influência se manifesta mesmo nos processos mais artesanais, como, por exemplo, na fotografia seriada do stop-motion.

\subsection{A Direção de Arte}

O planejamento da direção de arte assume uma importância muito maior na animação do que no cinema comum. Este contexto é justificado pelo gênero se posicionar como uma arte plástica que gera a ilusão de movimento. Assim, a direção de arte torna a capacidade diegética ${ }^{1}$ de qualquer conteúdo dependente das escolhas do realizador. É possível criar a totalidade do visual exposto na tela, selecionando o estilo gráfico, as cores, a arquitetura dos ambientes, a representação das personagens e a mistura de técnicas, entre outros aspectos, como define BUTRUCE (2005). O desafio da direção de arte está em criar uma coesão entre estes fatores e elementos para impressionar os sentidos dos usuários das mídias locativas.

\subsection{As mídias locativas}

A disseminação de conteúdos por meios digitais traz alternativas para o consumo de produtos audiovisuais. Observa-se uma contínua associação das possibilidades de distribuição de conteúdo entre antigas e novas plataformas, onde se destacam as mídias locativas. Nos dias atuais, sempre há um dispositivo capaz de solucionar a questão da distância e do espaço entre produtores e consumidores: uma garantia da audiência em todo lugar, em qualquer contexto. Ao mesmo tempo, os novos aparatos fornecem aos produtores informações sobre hábitos, comportamentos e as localizações de usuários, como assinala SANTAELLA (2008), em um contexto de convergência de meios jamais experimentado por qualquer fase da humanidade.

1 Referente à diegese. Forma do discurso constitutivo da narrativa. RABAÇA e BARBOSA (2001), pág. 504. 
As mídias locativas convertem-se em, assim, em um ambiente de exibição e de reflexão artística, virtualmente nas mãos dos espectadores/usuários, em tablets, laptops, telefones pessoais e demais aparatos que se multiplicam em capacidade de recebimento e transmissão de dados. Conclui-se, então, que o processo de planejamento e enquadramento de quaisquer cenas precisa sofre uma considerável influência da disparidade do tamanho das possíveis telas. Por isso, é importante refletir sobre as condições de veiculação e consumo.

\subsection{Hipermídia}

As mídias locativas, por utilizarem-se de arquivos digitais especializados em condensar informação em pequenos espaços de disco ou de banda, são as mais recentes plataformas, onde a "reprodutibilidade técnica", citada por Walter Benjamim, no século XIX, vem constituir uma nova vanguarda. O consumidor de conteúdo audiovisual é ejetado, por um clique, de um conceito de mídia, que serve para estabelecer um meio onde se fixa ou onde se transporta uma determinada informação ou conteúdo, até a hipermídia, onde a associação de meios de navegação cria uma nova forma de pensar a criação de um conteúdo de animação.

É para o ambiente cultural desta profusão de meios que um produtor de animação tornará comum uma narrativa, exercitando o papel disseminador que as mídias locativas executam. Considerar estes ambientes de consumo pode operar decisivamente na construção das alternativas artísticas do todo realizador. Não há como desconsiderar a cultura contemporânea de consumo e a associação de meios complementares da chamada cultura transmídia. Das grandes telas das salas de cinema até o visor de um aparelho de telefone celular, há fatores essenciais na avaliação de um produto audiovisual e que, aqui, busca-se elencar, provocando um ponto de reflexão sem, no entanto, constituir uma receita definitiva.

\subsection{0 festival Celucine}

A festival Celucine, fundado em 2008, é a maior base de lançamento de narrativas voltadas para o universo digital no Brasil. Para participar, cada realizador deve concordar em produzir um filme em equipamento digital à sua escolha, com tema livre. $O$ conteúdo deverá ter entre 30 segundos e três minutos de duração, sendo inédito em qualquer mídia. A exigência de que a história seja contada dentro de limites de tempo e de características de tamanho de arquivo representa uma boa indicação das qualidades técnicas apreciadas neste novo contexto.

Em sua quinta edição, no ano de 2012, o festival recebeu cerca de 170 filmes inscritos. O corpo de jurados, formado por membros do meio artístico e cultural da indústria do audiovisual, selecionou os finalistas. Os filmes são: "A Grande Fuga"; "O Colecionador"; "Noite Sangrenta"; "Vídeo Tirinha"; e "O Homem que Cantou as Aves do Sertão". A tabela a seguir apresenta o diretor de cada obra, seu tempo de duração, formato e tamanho do arquivo original encaminhado aos organizadores. 
Tabela 1 - Os finalistas da categoria animação

\begin{tabular}{|c|c|c|c|c|}
\hline Filme & Direção & Duração & Formato & Tamanho \\
\hline A grande fuga & Américo Gomes & 1'15" & Wmv & $15 \mathrm{Mb}$ \\
\hline O Colecionador & Dimitri Kozma & $1^{\prime} 00^{\prime \prime}$ & Avi & $22,3 \mathrm{Mb}$ \\
\hline Noite Sangrenta & Marco Nick & $2^{\prime} 47^{\prime \prime}$ & Mpeg4 & $26,9 \mathrm{Mb}$ \\
\hline Vídeo Tirinha & Munir Kanaan & $1^{\prime} 00^{\prime \prime}$ & $3 g p$ & $1,48 \mathrm{Mb}$ \\
\hline $\begin{array}{l}\text { O Homem que cantou } \\
\text { as aves do sertão }\end{array}$ & Patricia Oliveira & 2'59" & Avi & $21,6 \mathrm{mb}$ \\
\hline
\end{tabular}

Fonte: Elaborado pelo autor, com base na pesquisa realizada

\subsection{Objetivos e metodologia}

Não há uma fórmula definitiva para a classificação e avaliação dos produtos audiovisuais. Para isso, a pesquisa discorre, de forma analítica e comparativa, sobre as formas e texturas empregadas na criação de cada um dos vídeos da amostra, relacionando as opções compositivas com a base conceitual da psicologia da Gestalt. São analisadas as formas geométricas e icônicas dispostas no conteúdo relativamente ao binômio "simplicidade x força", onde as obras serão dispostas comparativamente, em relação ao conjunto das opções do artista.

A psicologia da Gestalt aponta que um determinado estímulo é mais bem percebido quando exige a menor quantidade de energia cerebral para se fazer significar dentro do ambiente. Há diversos princípios sustentados pelos teóricos para definir o processo de percepção ao que se submete determinado estímulo. O Princípio da Boa Pregnância, também conhecido como Princípio da Boa Forma, é um ponto de relevante análise para os produtos do universo amostral.

Ao expor visualmente quadros com frames selecionados, verificam-se as alternativas da direção de arte e seu impacto em uma área de exibição tão exígua quanto as telas dos dispositivos móveis portáteis. Utilizando conceitos de composição de quadro e emprego de cores e texturas, serão construídas análises de eficiência de determinadas opções de cada filme. Os finalistas ainda serão analisados individualmente, com respeito à natureza icônica de seu design cinematográfico e as influências visuais, como forma de proporcionar uma reflexão sobre o grupo social ao qual aquela obra busca referir-se, ao realizador e seus potenciais consumidores.

Em virtude disso, busca-se o foco na experiência do usuário, nas condições ambientais onde se dará o consumo do conteúdo e das características que este exibe para tornar-se mais "perceptível". A metodologia constrói uma análise comparativa e conceitual entre as amostras para, primeiro, analisar quais elementos empregados na composição do vídeo favorecem uma boa percepção e um bom entendimento da narrativa, cuja análise é feita em paralelo com a desconstrução da direção de arte empregada, ao refletir sobre os grupos culturais onde se planta a natureza artística da obra e as influências visuais herdadas de outras tradições, escolas ou grupos culturais.

Também será verificado se as opções da direção de arte aplicadas são adequadas ou não para que a fruição do consumo daquele conteúdo se dê até mesmo através de uma pequena tela de duas por duas polegadas. O método busca formar uma carga analítica qualitativa sobre a amostra determinada. 


\subsection{Análise e perspectivas}

O vencedor da edição 2012 do festival Celucine foi o vídeo "O homem que cantou as aves do sertão". Em sua construção, a obra usa cenários baseados no resultado da xilogravura da literatura de cordel nordestino. A simplicidade dos traços constrói uma paisagem interiorana em preto e branco e vai, sutilmente, ganhando cores de aquarela, para simbolizar os valores subjetivos da música de Luiz Gonzaga para o povo do Nordeste do Brasil. No sentido de percepção, as formas e as técnicas empregadas nesta obra são simples, remetendo diretamente à estética popular do cordel. Por si só, esta forma de manifestação popular é considerada um elemento de forte Gestalt, gerando um processo perceptível bastante favorável ao entendimento.

Uma técnica de desenho mais simples que a do filme vencedor está no vídeo "A grande fuga" - clara referência a uma estética infantilista, de inspiração naif, em função de suas formas e cores. O realizador valeu-se do traço forte nos contornos e cores básicas em todos os desenhos, alternativas de um cenário com poucos elementos, usado de forma quase icônica. A ilha deserta, as palmeiras, a areia e os personagens são apresentados com grande foco, representando uma encenação rígida e pouco disposta a proporcionar uma liberdade de interpretação. Trata-se de um produto de percepção facilitada, muito por causa da simplicidade do traço e do foco dos enquadramentos altamente rígidos do ponto de vista da economia de elementos.

O finalista "Noite sangrenta" apresenta uma narrativa mais complexa, buscando a construção de tensões, viradas e ganchos, algo muito comum em conteúdos mais longos e elaborados. $O$ vídeo conta a história de um lenhador solitário e, para informar o espectador do meio onde este personagem habita, apresenta um plano geral bastante elaborado e carregado de elementos, mostrando a floresta e situando a casa deste lenhador. A técnica empregada constitui a mistura de construção de objetos em 2D aplicados num ambiente simulando o $3 \mathrm{D}$, criado várias camadas dentro do mesmo enquadramento. Vale destacar que se trata de uma estética contemporânea, muito exercitada no contexto de peças publicitárias. O personagem lenhador é estilizado, com um tronco desproporcionalmente forte em relação ao restante do corpo. $O$ visual é rico, sob o ponto de vista de convivência pacífica entre as cores, que tem a seu favor a grande harmonia da estética ao longo de todo o vídeo, mas deixa transparecer o emprego de opções sutis e que tornam o processo de percepção um pouco mais oneroso para a audiência. A grande variedade de técnicas de desenho, ao mesmo tempo em que enriquece a estética, aumenta a necessidade de energia aplicada na percepção, dada a quantidade de detalhes visuais.

Do ponto de vista de arrojo estético e do emprego de elementos expressionistas, nenhum concorrente é mais desafiador do que "O colecionador". A narrativa se constrói com o emprego de uma técnica mista de desenhos 2D num ambiente cenográfico 3D, com a criação de diferentes níveis ocupados por figuras planas. O único personagem é desenhado de uma forma altamente caricatural, com traços fortes e expressionistas, buscando apresentar uma distorção visual nas formas e proporções capaz de representar algum desequilíbrio psicológico do mesmo. Nesta obra também são utilizadas texturas oriundas de fotografias reais como forma de composição dos objetos, até nos objetos de culto do colecionador, a saber, seus próprios excrementos. A utilização deste recurso representa a complexa psicologia da obra e combina com a técnica visual utilizada, mas gera um grande número de pontos 
de significação ao longo do com teúdo. Estes fatores, aliados, convergem para um produto de percepção mais complexa e, assim, de uma Gestalt mais fraca.

A obra "Vídeo tirinha" apresenta, a exemplo de seu título, uma ideia que reproduz uma história em quadrinhos com detalhes muito sutis de animação. Trata-se de uma animação 2D, com pouquíssimo movimento, valendo-se de personagens estáticos - uma velha senhora e as aranhas que ocupam sua casa. A evolução da história é, basicamente, a passagem do tempo representado pela quantidade de teias de aranhas construídas do primeiro ao último quadro, usadas para reforçar a sensação de abandono e de renúncia ao fim da vida da senhora. Neste período, a velha senhora não esboça movimentos, mantendo-se apenas atenta à televisão que exibe sua novela. O emprego de formas simples, com poucas variações de quadro e movimento, converteu-se num conjunto onde o contraste entre simplicidade de formas e sofisticação do discurso prejudicou a percepção do conteúdo. Bastante desafiadora do ponto de vista artístico, a missão de cruzar as linguagens audiovisual e das histórias em quadrinhos revelou um quadro onde a Gestalt pode ser considerada fraca.

Perceber que os conteúdos voltados para mídias locativas devem ter certas características de dimensão e proporções adequadas a pequenas telas é uma questão central na criação de um mercado forte para este segmento produtivo. $\mathrm{O}$ vídeo " $\mathrm{O}$ homem que cantou as aves do sertão" foi extremamente feliz nas opções de enquadramento e proporção. Os créditos de abertura são adequados para pequenas telas, como mostram as figuras 1 e 2 .

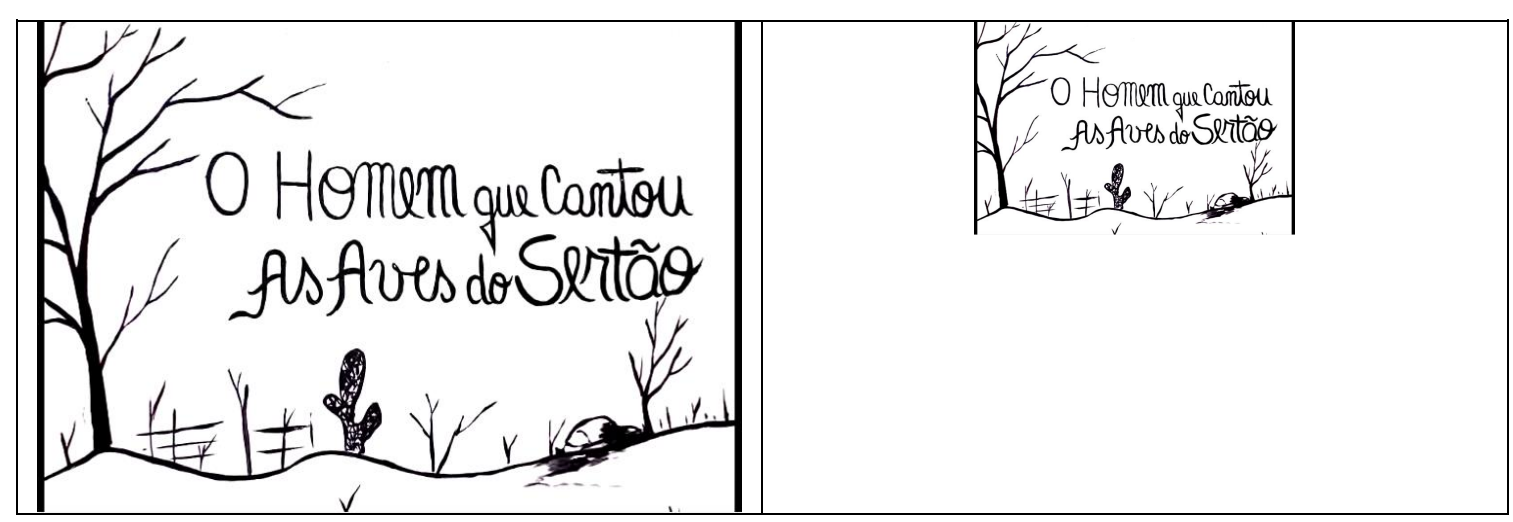

Figuras 1 e 2 - Créditos de abertura do filme "O homem que cantou as aves do sertão". Elaborado pelos autores, com base na pesquisa realizada.

A simplicidade do desenho e a economia nos detalhes ajudam a tornar mesmo os planos gerais bastante visualizáveis nas condições de análise. A evolução visual na narrativa respeita claramente as limitações de área de tela, pois mesmo os elementos apresentados com mais detalhes são imediatamente seguidos por planos mais fechados que ajudam a clarear detalhes que, no plano anterior, poderiam ser confusos ou não interpretados, como observado na entrada do personagem de Luiz Gonzaga carregado por pássaros e o plano apresentado em seguida. De um modo geral, apenas os créditos finais não foram pensados com limitação de tela, pois são ilegíveis nas condições de análise propostas.

O vídeo "A grande fuga" também é altamente coerente com a sua utilização em pequenas telas. Mesmo o plano geral do pássaro que sobrevoa uma ilha onde irá buscar descanso é simples, com proporções bem realizadas e desenhos icônicos, o que facilita a visualização em qualquer das utilizações do conteúdo. Um detalhe pequeno 
como a retirada da pena do pássaro azul é bem representado, com um plano fechado adequado para mostrar a ação, evidenciada nas figuras 3 e 4 . Ao contrário de "O homem que cantou as aves do sertão", "A grande fuga" apresenta créditos bem visualizáveis em pequenas telas, talvez pela opção de cores pretas em fundo branco, ao contrário do anterior.

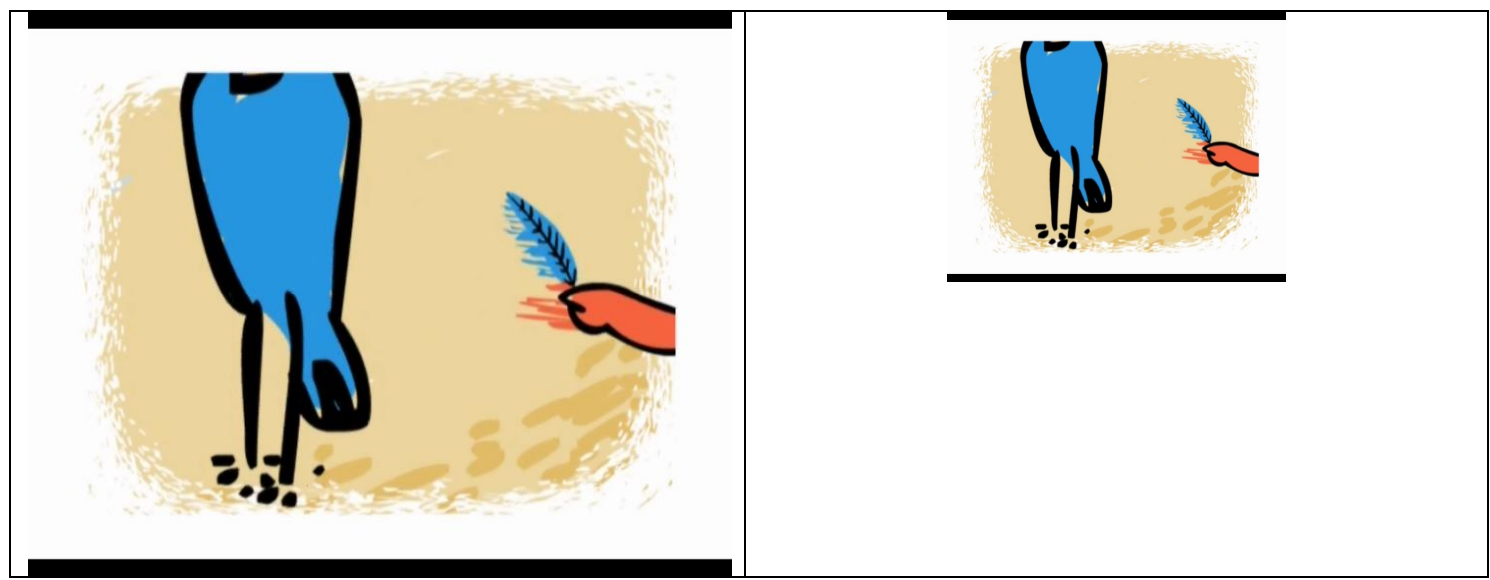

Figuras 3 e 4 - Cena do filme "A grande fuga". Elaborado pelos autores, com base na pesquisa realizada.

Já o vídeo "Noite sangrenta", por ser bem mais arrojado do ponto de vista de roteiro e possuir uma característica visual mais elaborada, merece algumas observações pontuais sobre as opções narrativas escolhidas. O plano geral inicial do vídeo é muito bem elaborado em formas e cores, mas, quando exibido em uma pequena tela, torna-se impossível perceber que o lenhador está chegando a casa. Esta constatação não indica que o plano seja incompreensível. Porém, seu detalhamento representa um desperdício narrativo em pequenas telas, na medida de que o personagem principal assume uma forma pouco visualizável dentro do contexto geral.

Um detalhe bastante complexo de ser mostrado são as gotas de sangue (mais tarde o espectador descobrirá que a substância verdadeira é molho de tomate) que pingam da poltrona. $O$ realizador conseguiu, com aplicação de alto contraste entre a cor do "sangue" e a atmosfera sombria, tornar visualizável mesmo este detalhe significativo para a evolução da narrativa. A mesma questão pode ser observada no plano que apresenta a saída do urso da casa, pois é muito difícil visualizar esta ação no plano que se segue ao da expulsão, indicado nas figuras 5 e 6 . Mas, desta vez, há um plano fechado de complemento ao anterior, o que atenua o desperdício de energia empregada no relato do plano geral, no início do vídeo.
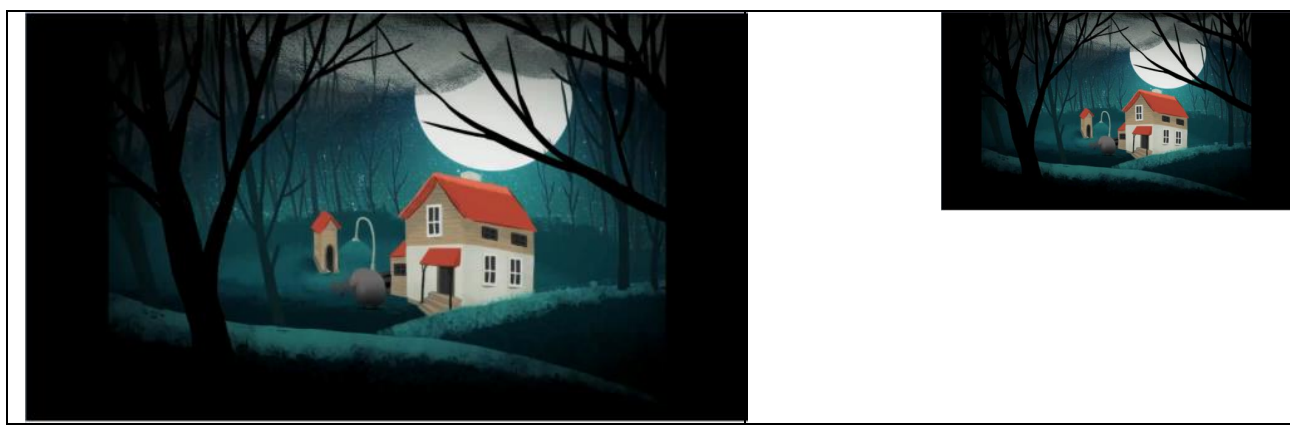

Figuras 5 e 6 - Cena do filme "Noite Sangrenta". Elaborado pelos autores, com base na pesquisa realizada. 
O vídeo "O colecionador", a exemplo de "Noite sangrenta", é bastante elaborado do ponto de vista de formato e arte, mas é também mais coerente com a ideia de exibição em pequenas telas do que o anterior. Um dos planos gerais mais complexos é o da saída do personagem único de dentro do banheiro com seu objeto de culto, representado nas figuras 7 e 8 . Este plano é imediatamente seguido por um plano detalhe que mostra o rosto do personagem, com uma correção de câmera para o vidro, onde aparecem detalhes do objeto de coleção. Toda a evolução visual da narrativa obedece a essa aparente compreensão do realizador dos conceitos de composição que precisam estar presentes num projeto audiovisual voltado para pequenas telas.
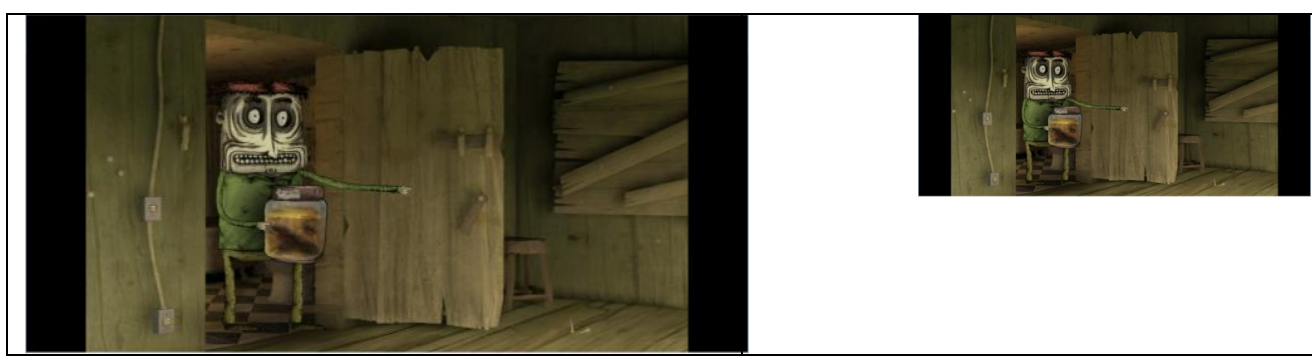

Figuras 7 e 8 - Cena do filme "O Colecionador". Elaborado pelos autores, com base na pesquisa realizada.

O conteúdo "Vídeo tirinha" é, basicamente, a evolução de tempo mostrada com o mesmo enquadramento. O problema de tornar visualizáveis as aranhas e as teias, apesar de serem pequenas em relação ao ambiente, foi contornado pelo uso eficiente do contraste entre a cor das teias e da aranha em relação ao fundo azulado da cena, sem prejuízo para o entendimento. A compreensão dos créditos, nesse caso, também fica prejudicada ao final, pois não há facilidade de visualização dos nomes dos realizadores dentro daquelas opções escolhidas de proporção para a assinatura do vídeo, mostradas nas figuras 9 e 10.

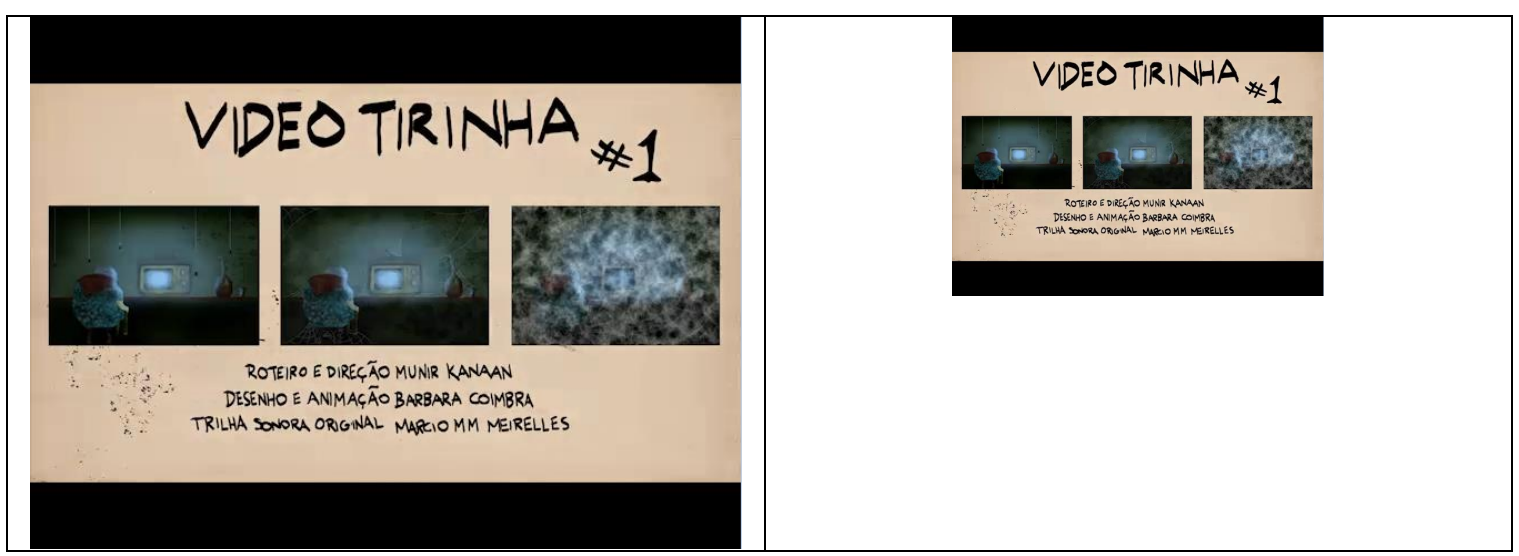

Figuras 9 e 10 - Frame dos créditos do filme "Video tirinha". Elaborado pelos autores, com base na pesquisa realizada.

De um modo geral, há sucesso na construção das narrativas dos finalistas do Celucine para aplicação em pequenas telas, estandardizadas aqui com a dimensão de duas por duas polegadas (cerca de $5 \mathrm{~cm} \times 5 \mathrm{~cm}$ ). Todos os vídeos finalistas, uns mais, outros menos, apresentam opções criativas prejudiciais a um processo de compreensão integral de seu conteúdo visual neste tipo de veiculação. 


\section{CONCLUSÃO}

A construção do universo de consumo para pequenas telas, apesar de estar em franco desenvolvimento, parece não despertar importância entre os realizadores, como espaço de expressão e de monetarização de produtos audiovisuais específicos. As mais vigorosas indústrias audiovisuais do mundo já compreenderam a lição de extrair receitas complementares das possibilidades de exibição disponíveis. Trata-se de um desafio ainda maior nesse contexto encontrar formas de adaptar conteúdos para este espaço de exibição limitado por algumas poucas polegadas de lado, como as telas dos dispositivos móveis portáteis.

A amostra privilegiada fornecida pelo Festival Celucine converteu-se em um excelente laboratório de análise da forma como o realizador brasileiro projeta seu conteúdo para consumo em mídias locativas. De um modo geral, o pensamento criativo ainda está condicionado para a grande tela ou para as tradicionais telas domésticas, onde questões de proporção de quadro e tamanho dos objetos são mais facilmente equalizáveis para ambas as áreas de exibição.

Quando ingressamos nas pequenas telas das mídias locativas somos levados a refletir sobre toda a arquitetura cenográfica e de cena, que sofre um impacto direto do tamanho limitado para a exibição de conteúdo, competindo com a diversidade de estímulos do ambiente urbano externo. Dessa forma, encontraram-se abundantes exemplos de desperdício narrativo nos conteúdos analisados, com informações e ações que não podem ser percebidas quando submetidas a uma limitação de tela de exibição, fato que comprova a ainda difícil compreensão da nova seara de exibição midiática pelos realizadores de animação no Brasil.

É bem provável que, pelo pouco potencial de remuneração deste segmento, os olhares dos artistas ainda não tenham sido influenciados pelas percepções que se buscou elencar aqui. Mas cabe perguntar se este aparente efeito não seria, isto sim, a causa da ainda baixa remuneração deste segmento. Talvez produtos com características mais próprias para pequenas telas sejam os indutores de uma nova ordem de consumo e de novas tendências para o mercado audiovisual.

A nova ordem de relação entre consumidor e produto audiovisual está em franca marcha, e já não podemos considerar a internet, as grandes redes das mídias locativas e suas características de consumo como algo novo para a realidade contemporânea da humanidade. Mas a mesma revolução proporcionada pelos meios técnicos ainda não repercutiu na gênese criativa coletiva, que ainda encontra-se situada, do ponto de vista imagético, junto a formas bem mais conservadoras de expressão e de venda de produtos audiovisuais.

Cabe provocar a arte e a técnica a serviço da realização de animação para que sejam capazes outra vez de surpreender a sociedade, subvertendo os conceitos e abrindo novas fronteiras de expressão, complementando a revolução tecnológica proporcionada pelos novos meios com a revolução narrativa que se impõe. As novas mídias locativas estão aí, nas mãos de todos, em todos os lugares, esperando por novas formas de surpreender e gerar emoções, constituindo uma nova fronteira para o ancestral desafio da expressão do sentido artístico humano. 


\section{REFERÊNCIAS}

ARAGÃO, Isabella R. "Ampliação das Configurações Gráficas no Cinema". Universidade Federal de Pernambuco - 2005. Disponível na internet por http em: <http://www.intercom.org.br/papers/nacionais/2005/resumos/R1965-1.pdf>. Acesso em 19 de maio de 2013.

ARNHEIN, Rudolf. Arte e Percepção Visual: uma psicologia da visão criadora. São Paulo: Pioneira Thomson Learning, 2005.

AZEVEDO, Célia. "Introdução ao Estudo das Cores". Notas de aula. Escola de Comunicação e Artes. Univercidade. , "Introdução ao Estudo da Percepção". Notas de aula. Escola de Comunicação e Artes. Univercidade.

Comunicação e Artes. Univercidade.

"Teoria Gestaltista da Percepção". Notas de aula. Escola de

BORGES, Gabriela; PUCCI JR., Renato Luiz; SOBRINHO, Gilberto Alexandre (orgs.). Televisão: Formas Audiovisuais de Fiç̧ão e de Documentário. Vol. 2. Campinas, São Paulo e Faro (Portugal): CIAC, 2002. Disponível na internet por http em: <http://www.avecpr.org.br/wp-content/uploads/2012/10/publication.pdf $>$. Acesso em 27 de abril de 2013.

BRASILIENSE, Danielle R. "Os sentidos midiáticos da ordem e da monstruosidade em Dexter". In: Revista E-compós, v.12, n.3, 2009. Disponível na internet por http em: <http://www.compos.org.br/seer/indeh.php/e-compos/article/viewfile/455/394>.

Acesso em 20 de abril de 2013

BUTRUCE, Débora L. V. "A Direção de Arte e a Imagem Cinematográfica". Universidade Federal Fluminense. 2005. Disponível na internet por http em: <http://www.bdtd.ndc.uff.br/tde busca/arquivo.php?codArquivo=1230>. Acesso em 19 de maio de 2013.

DONDIS, Donis A. Sintaxe da linguagem visual. São Paulo: Matins Fontes, 2002. Disponível na internet por http em: <http://www3.uma.pt/dmfe/DonDIs_sintaxe_da_Linguagem_Visual.pdf>. Acesso em 20 de abril de 2013.

GOSCIOLA, Vicente. Roteiro para as novas mídias: Do Cinema às Mídias Interativas. São Paulo: Ed. Senac. 2008.

JUSSAN, Claudia. "Design cinematográfico: a concepção visual do imaginário fantástico". Universidade Federal de Belo Horizonte. 2005. Disponível na internet por http em: <http://pt.scribd.com/doc/69263398/20648330-DISSERTACAO-Design-Cinematografico-Claudia-Jussan>. Acesso em 26 de maio de 2013.

LAZ-CASAS, Luiz F L. "Interferências Gráficas no Cinema”, 3ํ Congresso de Design da Informação. Ed. Rosari, 2007.

MACHADO, A. Pré-cinemas e pós-cinemas. Campinas: Papirus, 1997. 
MACHADO, A. e VÉLEZ, M. L. Questões Metodológicas Relacionadas com a análise da

televisão. Revista E-Compós, vol.8, 2007. Disponível na internet por http em: <http://www.compos.org.br/seer/index.php/e-compos/article/viewFile/123/124>. Acesso em 20 de abril de 2013.

NESTERIUK, Sergio. Dramaturgia de Serie de Animação. São Paulo: ANIMATV, 2011. Disponível em http://issuu.com/animatv/docs/dramaturgia de serie de animacao. Acesso em 12 de maio de 2013.

RABAÇA, Carlos Alberto e BARBOSA, Gustavo Guimarães. Dicionário de Comunicação. Rio de Janeiro: Campus, 2001. Nova edição revista e atualizada.

SANTAELLA, Lucia. “A Estética Política das Mídias Locativas". In: Nómadas, n.28. 2008. Disponível na internet por http em: <http://www.scielo.org.co/pdf/noma/n28/n28a13.pdf>. Acesso em 2 de junho de 2013.

TEIXEIRA, Carla C C. "Vinhetas de televisão: do estático ao pós-moderno". Artigo. 7음 Congresso Brasileiro de Pesquisa \& Desenvolvimento em Design. Paraná, 2006. Disponível na internet por http em: <http://www.maxwell.lambda.ele.puc-rio.br/8755/8755 1.PDF>. Acesso em 2 de junho de 2013.

TIETIZMANN, Roberto. Gênese dos Efeitos Visuais no Cinema. Intercom, V Congresso Nacional da História da Mídia. São Paulo, 2007. Disponível na internet por http em:

<http://www.ufrgs.br/alcar/encontros-nacionais-1/5o-encontro-2007-1/Genese\%20Dos\%20Efeitos\%20Visuais\%20No\%20Cinema.pdf>. Acesso em 13 de abril de 2013.

Sítio do festival Celucine: Disponível na internet por http em: <http://www.celucine.com.br>. Acesso em 10 de março de 2013. 